\title{
Epidermal Hyperplasia and Appendage Abnormalities in Mice Lacking CD109
}

\author{
Shinji Mii, ${ }^{,}$Yoshiki Murakumo, ${ }^{* \dagger}$ Naoya Asai, ${ }^{,}$ \\ Mayumi Jijiwa, ${ }^{*}$ Sumitaka Hagiwara, ${ }^{\S}$ \\ Takuya Kato, ${ }^{*}$ Masato Asai, ${ }^{*}$ Atsushi Enomoto, ${ }^{*}$ \\ Kaori Ushida, ${ }^{*}$ Sayaka Sobue, ${ }^{\text {" }}$ \\ Masatoshi Ichihara, ${ }^{\text {ๆ }}$ and Masahide Takahashi ${ }^{\star \neq}$ \\ From the Department of Pathology, ${ }^{*}$ and the Division of \\ Molecular Pathology, ${ }^{\ddagger}$ Center for Neurological Disease and \\ Cancer, and the Department of Oral and Maxillofacial \\ Surgery, Nagoya University Graduate School of Medicine, \\ Nagoya; the Department of Pathology, ${ }^{\dagger}$ Kitasato University \\ School of Medicine, Sagamihara; and the Department of \\ Biomedical Sciences, ${ }^{\text {T }}$ College of Life and Health Sciences, \\ Chubu University, Kasugai, Japan
}

CD109, a glycosylphosphatidylinositol-anchored glycoprotein, is highly expressed in several types of human cancer tissues, in particular, squamous cell carcinomas. In normal human tissues, human CD109 expression is limited to certain cell types including myoepithelial cells of the mammary, lacrimal, salivary, and bronchial glands and basal cells of the prostate and bronchial epithelium. Although CD109 has been reported to negatively regulate transforming growth factor- $\beta$ signaling in keratinocytes in vitro, its physiologic role in vivo remains largely unknown. To investigate the function of CD109 in vivo, we generated CD109-deficient $\left(\mathrm{CD}_{109^{-/}}\right)$mice. Although $\mathrm{CD}_{109^{-/-}}$mice were born normally, transient impairment of hair growth was observed. At histologic analysis, kinked hair shafts, ectatic hair follicles with an accumulation of sebum, and persistent hyperplasia of the epidermis and sebaceous glands were observed in $\mathrm{CD} \mathrm{O9}^{-/-}$mice. Immunohistochemical analysis revealed thickening of the basal and suprabasal layers in the epidermis of $\mathrm{CD}_{109^{-/-}}$mice, which is where endogenous CD109 is expressed in wild-type mice. Although CD109 was reported to negatively regulate transforming growth factor- $\beta$ signaling, no significant difference in levels of Smad2 phosphorylation was observed in the epidermis between wild-type and $C D 109^{-/-}$mice. Instead, Stat 3 phosphorylation levels were significantly elevated in the epidermis of $\mathrm{CD}_{109^{-/-}}$mice compared with wild- type mice. These results suggest that $\mathrm{CD109}$ regulates differentiation of keratinocytes via a signaling pathway involving Stat3. (Am J Pathol 2012, 181:1180-1189; http://dx.doi.org/10.1016/j.ajpath.2012.06.021)

CD109, a glycosylphosphatidylinositol-anchored cell surface glycoprotein, is a member of the $\alpha_{2}$-macroglobulin/ C3, C4, C5 family of thioester-containing proteins. ${ }^{1-4}$ CD109 is a cell surface antigen expressed on a subset of fetal and adult CD34 ${ }^{+}$bone marrow mononuclear cells, phytohemagglutinin-activated $\mathrm{T}$ lymphoblasts, thrombinactivated platelets, leukemic megakaryoblasts, endothelial cells, and mesenchymal stem cell subsets. ${ }^{5-7}$ In addition, human CD109 is expressed in a limited number of cell types in normal tissues such as myoepithelial cells of the mammary, lacrimal, salivary, and bronchial glands and basal cells of the prostate and bronchial epithelium. ${ }^{8-12}$ High levels of CD109 expression have also been detected in various tumor cell lines and in tumor tissues including squamous cell carcinomas (SCCs) of the lung, esophagus, uterus, and oral cavity; malignant melanoma of the skin; and urothelial carcinoma of the urinary bladder ${ }^{8-16}$ CD109 expression was significantly higher in well-differentiated SCCs of the oral cavity and in low-grade urothelial carcinomas of the urinary bladder than in moderately or poorly differentiated SCCs and in highgrade urothelial carcinomas, respectively. ${ }^{14,16}$ These findings suggest that CD109 expression is strictly controlled in normal tissues and is associated with tumor development.

Signals through the transforming growth factor (TGF)- $\beta$ receptor system induce a wide range of biological responses including cell proliferation, differentiation, migration, and apop-

Supported by Grants-in-Aid for Global Center of Excellence research, Scientific Research A (M.T.) and Scientific Research C (Y.M.), from the Ministry of Education, Culture, Sports, Science and Technology of Japan, and by the Toyoaki Scholarship Foundation (Y.M.).

Accepted for publication June 12, 2012

Supplemental material for this article can be found on http://ajp. amjpathol.org or at $h$ ttp://dx.doi.org/10.1016/j.ajpath.2012.06.021.

Address reprint requests to Masahide Takahashi, M.D., Ph.D., Department of Pathology, Nagoya University Graduate School of Medicine, 65 Tsurumai-cho, Showa-ku, Nagoya 466-8550, Japan. E-mail: mtakaha@med.nagoya-u. ac.jp. 
tosis; tissue remodeling; immune response; and angiogenesis. ${ }^{17-19}$ Ligand-mediated assembly of TGF- $\beta$ receptors I and II (TGFBRI and TGFBRII, respectively) initiates an intracellular phosphorylation cascade; activated TGFBRII transphosphorylates TGFBRI, which subsequently phosphorylates receptor-regulated Smads (R-Smads) such as Smad2/3, which in turn enables the R-Smads to bind a common mediator, Smad4. R-Smad/Smad4 complexes accumulate in the nucleus, where they act as transcription factors for target genes. ${ }^{20-22}$ TGF- $\beta$-mediated receptor activation also induces inhibitory Smads (I-Smads) such as Smad7, which compete with R-Smads in binding to activated TGFBRI, thereby negatively regulating signals. ${ }^{23}$

CD109 functions as a negative regulator of TGF- $\beta$ signaling in human keratinocytes; CD109, as a component of the TGF- $\beta$ receptor system, inhibits activation of RSmad, probably by direct modulation of receptor activity. ${ }^{24,25}$ Our recent study using cultured cells showed CD109 to be cleaved by furin, generating 180- and 25$\mathrm{kDa}$ fragments; the $180-\mathrm{kDa}$ fragment is partially secreted into the medium. ${ }^{26}$ The negative effect of CD109 on TGF- $\beta$ signaling requires this furin-mediated cleavage of CD109 because the resulting $180-\mathrm{kDa}$ fragment is responsible for this negative effect. ${ }^{26}$ CD109 associates with caveolin-1, a major component of caveolae, and promotes localization of TGFBRs into caveolar compartments to facilitate their degradation. ${ }^{27}$ Although these findings show the importance of CD109 in the TGF- $\beta$ signaling pathway in vitro, its physiologic functions in vivo have not yet been elucidated.

Recombinant CD109 regulates signal transducers and activators of transcription 3 (STAT3) activation in human keratinocytes. ${ }^{28}$ Various cytokines and growth factors, such as IL-6, IL-20, IL-22, and epidermal growth factor, activate STAT3 in keratinocytes, ${ }^{29,30}$ whereas TGF- $\beta$ suppresses STAT3 activation through IL-6 in epithelial cells. ${ }^{31,32}$ STAT3 is critical to such biological activities as cell proliferation, differentiation, migration, survival, and oncogenesis. ${ }^{29,30}$

In the present study, we generated CD109-deficient mice $\left(C D 109^{-1-}\right.$ mice $)$ to investigate the physiologic roles of CD109 in vivo. The CD109 ${ }^{-1-}$ mice showed transient impairment of hair growth, accompanied by kinked hair shafts, ectatic hair follicles with an accumulation of sebum, and persistent hyperplasia of the epidermis and sebaceous glands. These findings suggest that CD109 has a role in the normal development of skin.

\section{Materials and Methods}

\section{Targeting Construct}

Construction of the targeting vector started by modifying a pBlueScript II KS vector (Agilent Technologies, Inc., Santa Clara, CA) containing a LacZ reporter with a mouse nuclear localization signal upstream of a phosphoglycerine kinase $(P G K)$ promoter driving a neomycin-resistant gene (neo) selection marker. The CD109 5' homology arm (1666 bp) was generated via PCR with PfuUltra HighFidelity DNA polymerase (Agilent Technologies) using
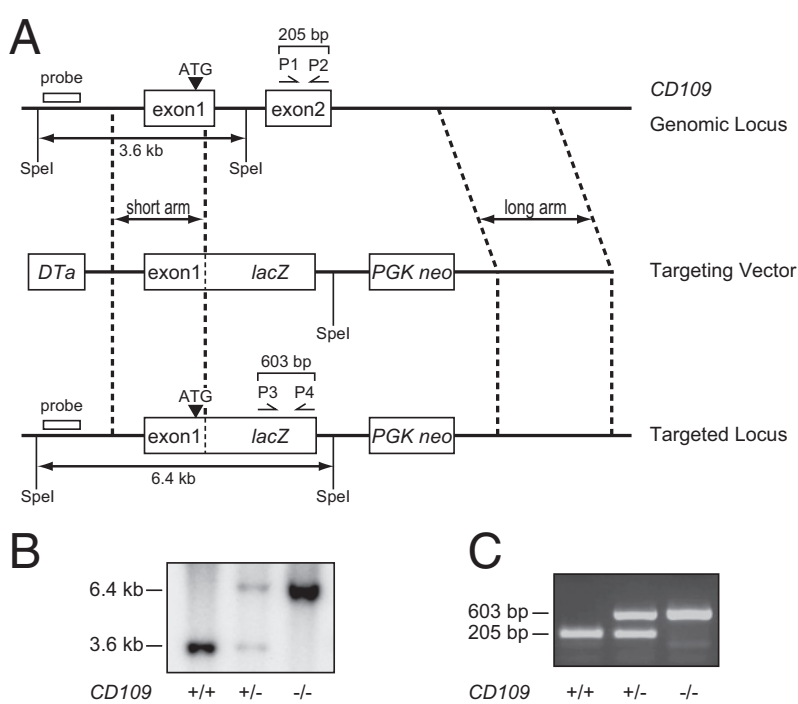

Figure 1. Generation of mice lacking CD109. A: Schematic representation of the targeting vector. A portion of exon 1 and all of exon 2 were replaced by the lacZ-PGK-neo cassette, which was placed in-frame with the ATG start codon of CD109 (closed triangle). DTa, diphtheria toxin A gene; neo, neomycin-resistant gene. B: Mouse genotyping via Southern blot analysis SpeI-digested genomic DNA isolated from the tails of wild-type $(+/+)$ heterozygous $(+/-)$, and homozygous $(-/-)$ CD109 mice were hybridized using the $5^{\prime}$ probe shown in A. SpeI digestion yielded a $3.6-\mathrm{kb}$ fragment for the wild-type allele and a 6.4-kb fragment for the mutant allele. C: Mouse genotyping using PCR. Primer positions are indicated by arrows (P1 - P4) in A. PCR products amplified with P1 and P2 (wild-type allele) are $205 \mathrm{bp}$, and those with P3 and P4 (mutant allele) are 605 bp.

genomic DNA of the $129 \mathrm{~S} 6$ mouse strain as a template and inserted into the EcoRV site of the vector. The CD109 3 ' homology arm (4893 bp) of intron 2 was inserted into the Notl site. This targeting vector (Figure $1 \mathrm{~A}$, middle) for the CD109 locus (Figure 1A, top) was designed to insert a lacZ-PGK-neo cassette 17 amino acids downstream from the methionine start, resulting in disruption of the remainder of the first coding exon and the entire second exon. Structure of the targeted CD109 allele is shown in Figure $1 \mathrm{~A}$ (bottom). The final targeting vector was confirmed via DNA sequencing and restriction mapping.

\section{Generation of CD109 Knockout/lacZ Knockin Mice}

The targeting vector was linearized by digestion with $\mathrm{Kpnl}$, and introduced by electroporation into embryonic stem cells derived from 12956 mice. After G418/diphtheria toxin A positive/negative selection, 10 embryonic stem cell clones with successful homologous recombination were isolated via Southern blot screening of Spel-digested genomic DNA with a $5^{\prime}$ probe (Figure $1 \mathrm{~A}$ ). One clone was injected into C57BL/6J blastocysts; chimeric mice were generated by PhoenixBio Co., Ltd. (Higashihiroshima, Japan). The genetic background of the mice used in the present study was C57BL6J/129S6. All mice were housed in polycarbonate cages containing hardwood chip bedding, at $25^{\circ} \mathrm{C}$ on a 12-hour light-dark cycle. All animal protocols were approved by the Animal Care and Use Committee of Nagoya University Graduate School of Medicine (approval ID number 23121). 
Table 1. List of Primary Antibodies

\begin{tabular}{llllll}
\hline Antibodies to & \multicolumn{1}{c}{ Clone } & \multicolumn{1}{c}{ Source } & Application & Dilution & Pretreatment \\
\hline CD109 & C-9/mouse monoclonal & Santa Cruz Biotechnology & Immunoblotting & $1: 1000$ & NA \\
CD109 & M-250/rabbit polyclonal & Santa Cruz Biotechnology & Immunoperoxidase & $1: 500$ & Autoclave \\
Smad7 & H-79/rabbit polyclonal & Santa Cruz Biotechnology & Immunofluorescence & $1: 20$ & Water bath \\
$\beta$-Actin & AC-74/mouse monoclonal & Sigma-Aldrich & Immunoblotting & $1: 5000$ & NA \\
CD3 & Rabbit polyclonal & Dako & Immunoperoxidase & $1: 500$ & Water bath \\
CD45R & RA3-6B2/rat monoclonal & eBioscience & Immunoperoxidase & $1: 3200$ & Water bath \\
Gr-1 & RB6-8C5/rat monoclonal & eBioscience & Immunoperoxidase & $1: 100$ & Proteinase K, room \\
& & & & temperature for \\
p63 & & & & 10 min \\
CK10 & 4A4/mouse monoclonal & Sigma-Aldrich & Immunoperoxidase & $1: 100$ & Water bath \\
CK14 & Rabbit polyclonal & Covance & Immunoperoxidase & $1: 1000$ & Water bath \\
Filaggrin & AF64/rabbit polyclonal & Covance & Immunoperoxidase & $1: 1000$ & Water bath \\
BrdU & Rabbit polyclonal & Covance & Immunoperoxidase & $1: 500$ & Water bath \\
& B44/mouse monoclonal & BD Biosciences & Immunoperoxidase & $1: 100$ & 2 nmol/L HCl, room \\
& & & & temperature for \\
C-caspase-3 & Rabbit polyclonal & Cell Signaling Technology & Immunoperoxidase & $1: 100$ & Water bath \\
pSmad2 & Rabbit polyclonal & Cell Signaling Technology & Immunofluorescence & $1: 100$ & Water bath \\
(Ser465/467) & & & Immunoblotting & $1: 1000$ & NA \\
Smad2 & Mouse monoclonal & Cell Signaling Technology & Immunoblotting & $1: 1000$ & NA \\
pStat3 (Tyr705) & Rabbit monoclonal & Cell Signaling Technology & Immunofluorescence & $1: 20$ & Water bath \\
& & & Immunoblotting & $1: 2000$ & NA \\
Stat3 & Rabbit monoclonal & Cell Signaling Technology & Immunoblotting & $1: 2000$ & NA \\
\hline
\end{tabular}

NA, not applicable.

\section{Genotyping of Mice After Germline Transmission}

Genomic DNA from offspring was extracted from their tails. Genotyping of mice was performed via PCR, based on four primers: primer P1 (forward), 5'-GTCCCGCTTTCTGGTGACAG-3'; primer P2 (reverse), 5'-GTGTGACTGTTAGACAGTGCAG-3'; primer P3 (forward), 5'CCATCGCCATCTGCTGCACG-3'; and primer P4 (reverse), 5'-ACGATCCTGAGACTTCCACAC-3' (Figure 1A). The PCR with rTaq polymerase (Takara Bio Inc., Ohtsu, Japan) was performed as follows: $96^{\circ} \mathrm{C}$ for 2 minutes; 32 cycles of $94^{\circ} \mathrm{C}$ for 30 seconds, $65^{\circ} \mathrm{C}$ for 30 seconds, and $72^{\circ} \mathrm{C}$ for 30 seconds. The expected PCR product sizes from wild-type and targeted alleles were 205 and $603 \mathrm{bp}$, respectively.

\section{Tissue Preparation}

After body weight measurement, mice were sacrificed under general anesthesia. Complete necropsies were performed, and resected organs were cut into $5-\mathrm{mm}^{3}$ specimens and quickly frozen for protein extraction.

\section{Antibodies}

Primary antibodies used in the present study included anti-CD109 and anti-Smad7 monoclonal or polyclonal antibodies (Santa Cruz Biotechnology, Inc., Santa Cruz, CA); anti- $\beta$-actin and anti-p63 monoclonal antibodies (Sigma-Aldrich Corp., St. Louis, MO); anti-CD3 polyclonal antibody (Dako, Glostrup, Denmark), anti-CD45R and anti-Gr-1 monoclonal antibodies (eBioscience, Inc., San Diego, CA); anti-CK10, anti-CK14, and anti-filaggrin polyclonal antibodies (Covance, Inc., Princeton, NJ); anti-
BrdU (5'-bromo-2'-deoxyuridine) monoclonal antibody (BD Biosciences, San Jose, CA); and anti-cleaved caspase-3, anti-phospho-Smad2 (pSmad2), anti-Smad2, anti-phospho-Stat3 (pStat3), and anti-Stat3 monoclonal or polyclonal antibodies (Cell Signaling Technology, Inc., Danvers, MA). Alexa Fluor 488-conjugated anti-rabbit IgG secondary antibody was purchased from Invitrogen Corp. (Carlsbad, CA), and horseradish peroxidase-conjugated anti-rabbit IgG secondary antibody was purchased from Dako (Table 1).

\section{Western Blot Analysis}

Frozen mouse tissues were homogenized in SDS sample buffer $(62.5 \mathrm{mmol} / \mathrm{L}$ Tris $\mathrm{HCl}$ [pH 6.8], 2\% SDS, 25\% glycerol, and $20 \mu \mathrm{g} / \mathrm{mL}$ bromophenol blue) and sonicated until the tissues were no longer viscous. After measuring protein concentration using the DC Protein Assay Kit (Bio-Rad Laboratories, Inc., Hercules, CA), the lysates were boiled at $100^{\circ} \mathrm{C}$ for 2 minutes in the presence of $2 \%$ $\beta$-mercaptoethanol. The lysates, containing $40 \mu \mathrm{g}$ proteins, were subjected to SDS-PAGE and transferred to polyvinylidene fluoride membranes (Millipore Corp., Bedford, MA). Membranes were blocked for 1 hour at room temperature in Blocking One (Nacalai Tesque, Inc., Kyoto, Japan) with gentle agitation, and incubated with the primary antibody for 1 hour at room temperature. After the membranes were washed three times with Tris-buffered saline solution and Tween 20 buffer $(20 \mathrm{mmol} / \mathrm{L}$ Tris $\mathrm{HCl}$ [pH 7.6], $137 \mathrm{mmol} / \mathrm{L} \mathrm{NaCl}$, and 0.1\% Tween 20), they were incubated with secondary antibody conjugated to horseradish peroxidase for 1 hour at room temperature. After the membranes were washed, the reaction was visualized using the ECL Detection Kit (GE Healthcare, 
Buckinghamshire, UK) according to the manufacturer's instructions.

\section{Histologic Analysis}

The major organs were resected as described above. All tissues were fixed in 10\% neutral-buffered formalin, dehydrated, and embedded in paraffin. Sections $4 \mu \mathrm{m}$ thick were prepared for H\&E staining (which was performed using conventional methods) and immunohistochemistry $(\mathrm{IHC})$. Epidermal thickness of the dorsal skin was measured from the basal lamina to the lower border of the stratum corneum using WinROOF software version 5.04 (Mitani Corp., Fukui, Japan). Lipid accumulation was visualized via Oil Red O (Sigma-Aldrich) staining on frozen sections of formalin-fixed skin tissues.

\section{In Situ Hybridization}

After anesthetization, the mice were perfused intravascularly with $4 \%(\mathrm{w} / \mathrm{v})$ paraformaldehyde solution, and organs were resected and frozen in 2-methylbutane cooled in liquid nitrogen. Frozen sections $10 \mu \mathrm{m}$ thick were prepared using a cryostat (Leica Microsystems GmbH, Wetzlar, Germany).

CD109-specific PCR products of $\sim 400$ bp with SP6 and $\mathrm{T7}$ promoter fragments were generated using primers 5'-CCAAGCTATTTAGGTGACACTATAGAGAAGTGAACCTTCTCAGTGGC-3' and 5'-TGAATTGTAATACGACTCACTATAGGGGCACAAAGTACAGAAGGACGG-3'. The PCR products were gel purified and transcribed in vitro using SP6 or T7 RNA polymerase (Roche Applied Science, Penzberg, Germany) incorporating ${ }^{33}$ P-UTP (PerkinElmer, Inc., Waltham, MA). SP6 RNA polymerase generated the sense probe as a control, and T7 RNA polymerase generated the antisense probe. The probes were subsequently DNase treated and purified using the RNeasy Mini Kit (QIAGEN, Hilden, Germany). Slides were hybridized overnight at $60^{\circ} \mathrm{C}$ using $200 \mu \mathrm{L}$ per slide hybridization solution consisting of $1 \times 10^{6} \mathrm{cpm}$ radiolabeled probe and hybridization buffer (50\% formamide, $10 \%$ dextran sulfate, $0.5 \mathrm{~mol} / \mathrm{L} \mathrm{NaCl}, 1 \times$ Denhardt's solution, $10 \mathrm{mmol} / \mathrm{L}$ Tris $[\mathrm{pH}$ 8.0], $1 \mathrm{mmol} / \mathrm{L}$ EDTA, 500 $\mu \mathrm{g} / \mathrm{mL}$ yeast transfer RNA, and $10 \mathrm{mmol} / \mathrm{L}$ dithiothreitol). After hybridization, slides were immersed in $2 \times$ standard saline citrate solution for 15 minutes at room temperature, and RNase buffer $(20 \mu \mathrm{g} / \mathrm{mL}$ RNase A, $0.5 \mathrm{~mol} / \mathrm{L} \mathrm{NaCl}, 10$ $\mathrm{mmol} / \mathrm{L}$ Tris [pH 8.0], and $1 \mathrm{mmol} / \mathrm{L}$ EDTA) for 30 minutes at $37^{\circ} \mathrm{C}$. After intensive washing and dehydration, slides were dipped in twice-diluted Kodak Autoradiography Emulsion (type NTB; Eastman Kodak Co., Rochester, NY) and dried at room temperature for 30 minutes in a darkroom. Slides were then stored at $4^{\circ} \mathrm{C}$ for approximately 2 weeks in the dark, and were developed using Kodak D19 Developer and Fixer (Eastman Kodak).

\section{Immunohistochemistry}

Paraffin sections were prepared as described above. Slides were deparaffinized in xylene, and rehydrated in a graded series of ethanol. For antigen retrieval, they were immersed in Target Retrieval Solution [pH 9.0] (Dako) and heated for 15 minutes at $121^{\circ} \mathrm{C}$ via autoclaving or incubated for 30 minutes at $100^{\circ} \mathrm{C}$ in a water bath. In the case of staining with anti-Gr-1 antibody, slides were pretreated with proteinase K (100 $\mu \mathrm{g} / \mathrm{mL}$; Wako Pure Chemical Industries, Ltd., Osaka, Japan) for 10 minutes at room temperature for antigen retrieval. Nonspecific binding was blocked with $10 \%$ normal goat serum for 10 minutes at room temperature. Sections were incubated with primary antibodies for 1 hour at room temperature. Endogenous peroxidase was inhibited using 3\% hydrogen peroxide in PBS for 15 minutes. The slides were incubated with the secondary antibody conjugated to horseradish peroxidase-labeled polymer (EnVision+; Dako) for 15 minutes at room temperature, except for the slides incubated with anti-CD45R or anti-Gr-1 antibodies, which were incubated with $\mathrm{N}$-Histofine Simple Stain Mouse MAX PO (Rat) (Nichirei Biosciences, Inc., Tokyo, Japan), for 30 minutes at room temperature. Reaction products were visualized using diaminobenzidine (Dako); nuclear counterstaining was performed using hematoxylin.

\section{BrdU Incorporation Analysis}

Wild-type $\left(\mathrm{CD}_{109^{+/+}}\right)$and homozygous $\left(\mathrm{CD} 109^{-/-}\right)$ mice were injected intraperitoneally with BrdU (SigmaAldrich), $5 \mathrm{mg}$ per $100 \mathrm{~g}$ body weight, at postnatal day (P) 14 and P28. After 2 hours, the mice were sacrificed under general anesthesia, and dorsal skin was resected. The skin tissues were fixed in 10\% neutral-buffered formalin, dehydrated, and embedded in paraffin. Sections 4 $\mu \mathrm{m}$ thick were prepared on slides. The slides were deparaffinized, rehydrated, and immersed in $2 \mathrm{~mol} / \mathrm{L} \mathrm{HCl}$ for 30 minutes at room temperature for antigen retrieval. Immunohistochemical analysis using anti-BrdU antibody was performed as described above.

\section{Immunofluorescence Staining}

Deparaffinization, hydration, antigen retrieval, and blocking steps were performed as described above. The sections were incubated with primary antibody for 2 hours at room temperature. The slides were incubated with Alexa Fluor 488 (1:500)-labeled secondary antibody for 30 minutes at room temperature. The images were visualized under a fluorescence microscope (Olympus Corp., Tokyo, Japan).

\section{Cell Culture}

Both wild-type and CD109-deficient keratinocytes were isolated from neonatal (PO) dorsal skin using the CELLnTEC Advanced Cell Systems (CELLnTEC, Bern, Switzerland). They were maintained in fully defined, lowcalcium (0.07 mmol/L) medium, CnT-07 (CELLnTEC) in an incubator at $37^{\circ} \mathrm{C}$ and $5 \% \mathrm{CO}_{2}$. They were then subcultured via trypsinization and plated on $3.5-\mathrm{cm}$ dishes in CnT-07 medium. At $70 \%$ to $80 \%$ confluency, cells were starved for 6 hours in medium free of growth factor. They were washed once, treated with $0.1 \mathrm{nmol} / \mathrm{L}$ 
TGF- $\beta_{1}$ (PeproTech, Inc., Rocky Hill, NJ) for 1 to 4 hours, and then lysed as described above.

\section{In Vivo Wound Healing Assay}

Male CD109 ${ }^{+/+}$and CD109-/- sibling mice (approximately 22 to $28 \mathrm{~g}$ body weight and 8 to 12 weeks old) were anesthetized; their dorsal skin was shaved and swabbed with $70 \%$ ethanol before the procedure. For wounding, 4-mm punch biopsies (Kai Industries Co., Ltd., Seki, Japan) were performed on the shaved area. Wounds were separated by a minimum of $6 \mathrm{~mm}$ of uninjured skin. The diameter of the wound areas was measured at $0,1,3,5$, and 7 days after wounding, and wound closure was evaluated as a percentage of the initial wound size.

\section{Statistical Analysis}

The Student's $t$-test was used to analyze differences in epidermal thickness, wound healing, and IHC-positive ratios between $C D 109^{-/-}$and $C D 109^{+/+}$mice. $P<0.05$ was considered significant.

\section{Results}

\section{Generation of CD109 Knockout/lacZ Knockin Mice}

To inactivate the CD109 gene, we engineered a targeting vector in which the $3^{\prime}$ part of exon 1 and the entire exon 2 were replaced with a lacZ-PGK-neo cassette (Figure 1A). The lac $Z$ sequence was placed in-frame with the start codon of CD109. Male chimeras were generated from one of the targeted embryonic stem cell clones, and germline transmission of the targeted locus was ascertained by mating to C57BL/6J females. The genotypes of wild-type $\left(C D 109^{+/+}\right)$, heterozygous $\left(C D 109^{+/-}\right)$, and homozygous $\left(C D 109^{-/-}\right)$ mice were determined using Southern blot analysis (Figure $1 \mathrm{~B}$ ) and PCR (Figure 1C). Both heterozygous and homozygous mice were born normally, and there was no significant difference in body weight or life span among wild-type, heterozygous, and homozygous mice.

\section{Mouse CD109 Is Expressed in Skin and Testes}

To assess tissue distribution of CD109, whole lysates from various organs of $C D 109^{+/+}$and $C D 109^{-1-}$ mice were prepared and subjected to Western blot analysis using anti-CD109 antibody. Two bands with molecular masses of $\sim 150$ and $\sim 180 \mathrm{kDa}$ were detected in the lysates from skin and testes of $\mathrm{CD}_{109^{+/+}}$mice, but were undetectable in $C D 109^{-1-}$ mice, indicating that the two bands were CD109-specific (Figure 2A). The bands detected in cerebrum, cerebellum, and liver were nonspecific because they were detected in both $C D 109^{+/+}$and CD109 ${ }^{-1-}$ mice. CD109 mRNA expression in the skin and testes was also examined via in situ hybridization. CD109specific signal was detected in the epidermis and the seminiferous tubules of $\mathrm{CD}_{109^{+/+}}$mice but not in CD109-1- mice (Figure 2B).
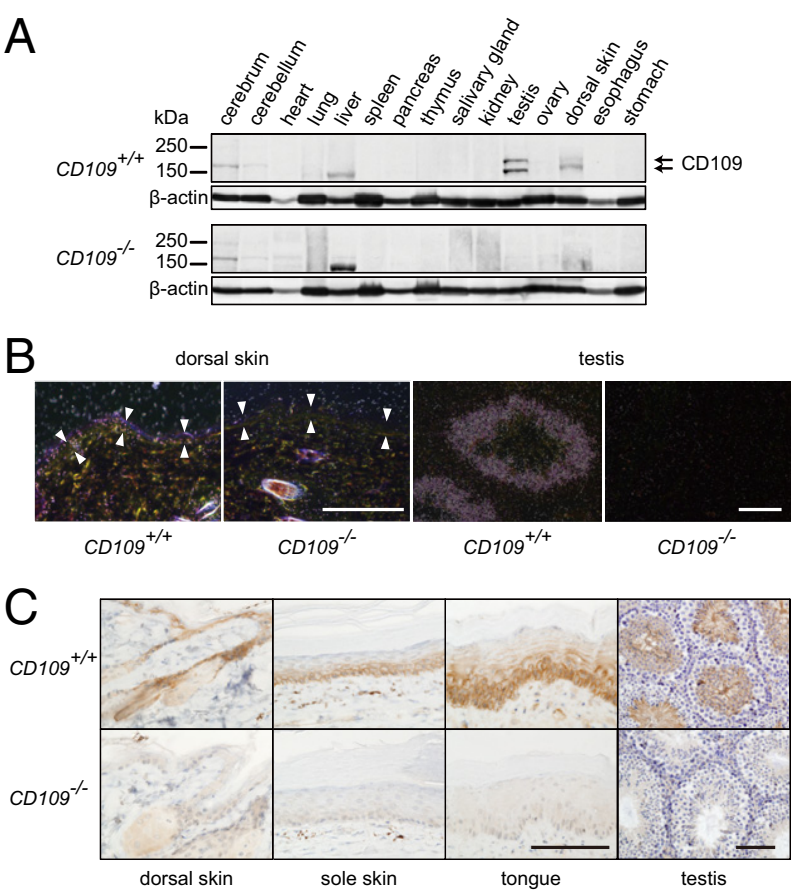

Figure 2. CD109 is expressed in the skin and testes in mice. A: Western blot analysis for CD109 expression in various tissues of adult $C D 109^{+/+}$and $\mathrm{CD}_{109^{-/-}}$sibling mice. CD109-specific bands of $\sim 150$ and $\sim 180 \mathrm{kDa}$ were detected in the skin and testes of $\mathrm{CD}_{109^{+/+}}$mice (arrows), but were undetectable in $C D 109^{-1-}$ mice. Blots probed with anti- $\beta$-actin antibody are shown as a loading control. B: In situ hybridization for CD109 mRNA expression in the skin and testes. ${ }^{33}$ P-labeled antisense ribonucleotide probes for $C D 109$ were hybridized to frozen sections of the skin and testes of 6-week-old $C D 109^{+/+}$and $C D 109^{-/-}$mice. CD109 mRNA was detected in the epidermis of the skin and the seminiferous tubules of the testes of $\mathrm{CD}_{109^{+/+}}$mice but not in $\mathrm{CD}_{109^{-1-}}$ mice. Arrowheads indicate the boundary of the epidermis. Signals were captured via darkfield microscopy. Scale bars $=100 \mu \mathrm{m}$. C: Immunohistochemical analysis of CD109 expression in mice. CD109 protein is expressed in the squamous epithelium of the skin and tongue and the seminiferous tubules of the testes of adult $C D 109^{+/+}$ mice but not in $C D 109^{-1-}$ mice. Images of dorsal skin, sole skin, and tongue are the same magnification. Scale bars $=100 \mu \mathrm{m}$.

We subsequently performed $\mathrm{ICC}$ analysis of endogenous CD109 protein expression in various mouse tissues. CD109 protein was expressed in squamous epithelium of the skin and tongue, and seminiferous tubules of the testes in $C D 109^{+/+}$mice but not $C D 109^{-/-}$mice (Figure $2 \mathrm{C}$ ). CD109 expression was detected in the basal and suprabasal layers of the epidermis, including the infundibular portion of the hair follicle (Figure 2C). Tissue distribution of CD109 was compatible with the results of X-gal staining for LacZ expression in CD109-deficient (lacZ knockin) mice (data not shown). Mouse CD109 expression was not detected in either myoepithelial cells of the mammary and salivary glands or in bronchial basal cells.

\section{CD109 ${ }^{-1-}$ Mice Exhibit Transient Impairment of Hair Growth}

Macroscopically, impairment of hair growth in CD109 mice was first observed at P7, and persisted until P28 (Figure 3A). Hair of CD109-1- mice was much sparser and less directed than hair of $C D 109^{+/+}$mice. Hair growth then recovered, and no severe impairment was 


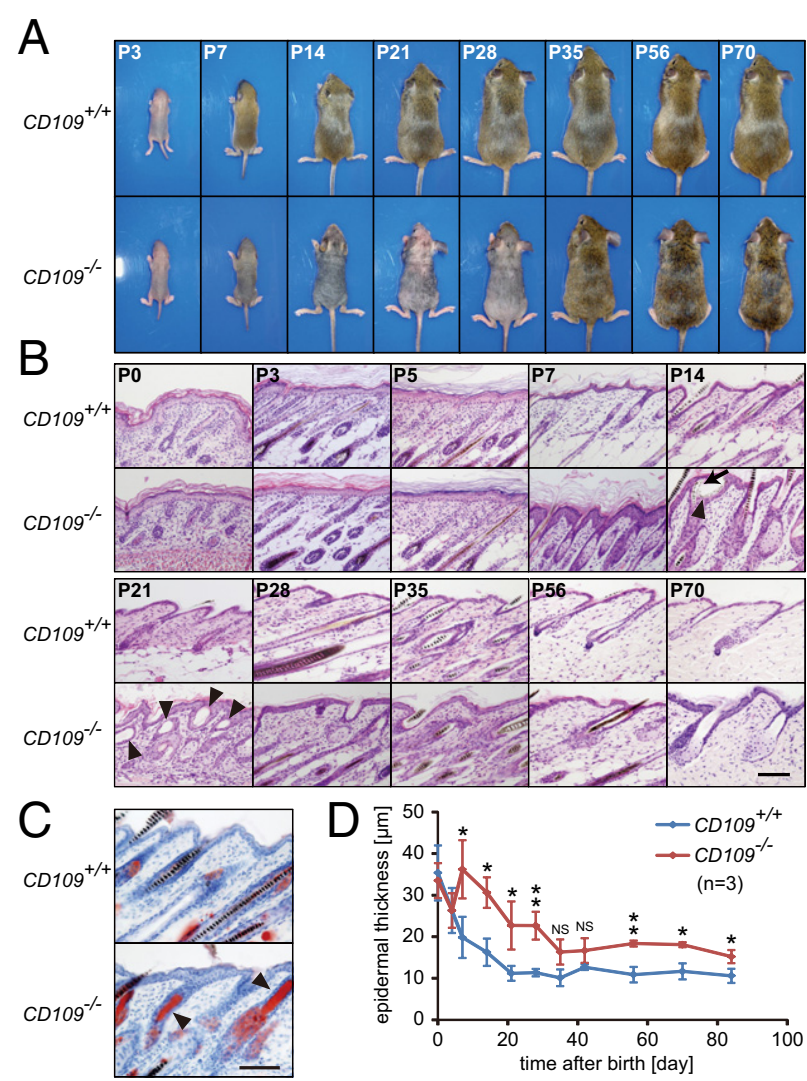

Figure 3. $\mathrm{CD} 109^{-/-}$mice develop skin abnormalities. A: Macroscopic images of hair growth impairment in a $\mathrm{CD} 109^{-/-}$mouse. Images of the dorsal skin of a $C D 109^{-1-}$ mouse and its $C D 109^{+/+}$sibling were obtained every 7 days (not all images are shown). Impairment of hair growth in the $C D 109^{-1-}$ mouse was apparent from P7 to P28, but then hair growth recovered, and no severe impairment was observed after P35. B: Microscopic images of skin abnormalities in $C D 109^{-1-}$ mice. H\&E-stained sections of the dorsal skin were prepared from $C D 109^{+/+}$and $C D 109^{-1-}$ mice at each age. Hair follicles of $\mathrm{CD} 09^{-1-}$ mice exhibited ectasia from P14 to P21 (arrowheads), and hair shafts were kinked at P14 (arrow). Hyperplasia of the epidermis and sebaceous glands was first observed at P7, and remained at P70. All images are the same magnification. Scale bar $=100 \mu \mathrm{m}$. C: Oil Red O staining of the skin of $C D 109^{+/+}$and $C D 109^{-/-}$mice. Accumulation of sebum in the ectatic hair follicles was apparent in $C D 109^{-/-}$mice at P14 (arrowheads). Scale bar $=50 \mu \mathrm{m}$. D: Comparison of epidermal thickness between $C D 109^{+/+}$and $C D 109^{-1-}$ mice. H\&E-stained sections of the dorsal skin were prepared from $C D 109^{+/+}$and $C D 109^{-/-}$mice at each age $(n=$ 3), and epidermal thickness of interfollicular epidermis was measured as described in Materials and Methods. Values are given as mean \pm SD. NS, not significant. ${ }^{*} P<0.05 ;{ }^{* * *} P<0.01$.

observed after P35 (Figure 3A). However, hair direction remained irregular in $C D 109^{-1-}$ mice after P35. All CD109-/- mice exhibited the same phenotype to varying degrees. CD109 ${ }^{-1-}$ mice, generated from CD109 ${ }^{+/-}$ mice backcrossed 10 times to the C57BL/6J strain, also showed the same phenotype, eliminating the influence of mouse genetic background of C57BL6J/129S6. No apparent abnormalities were observed in other organs, including testes in $C D 109^{-1-}$ mice.

\section{CD109 Deficiency Results in Epidermal Hyperplasia and Appendage Abnormalities}

To examine histologic aberrations causing transient impairment of hair growth in $C D 109^{-1-}$ mice, H\&E-stained skin specimens were prepared from P0 to P70 CD109+/+ and $C D 109^{-1-}$ mice (Figure 3B). There were no apparent differences in hair follicles between $C D 109^{+/+}$and CD109 ${ }^{-1-}$ mice at P0, P3, and P5 (Figure 3B; see also Supplemental Figure S1 at http://ajp.amjpathol.org) or in inferior segments of hair follicles at P7 (see Supplemental Figure S1 at http://ajp.amjpathol.org). At P14, some hairs of $C D 109^{-1-}$ mice failed to penetrate the epidermis, and their shafts were kinky or zigzagged (Figure 3B), whereas all hairs of $\mathrm{CD}_{109^{+/+}}$mice penetrated the epidermis. Many hair follicles of $C D 109^{-1-}$ mice at P21 were ectatic; some did not have hair shafts (Figure 3B). However, the number of hair follicles did not significantly differ between CD $109^{+/+}$and CD109 ${ }^{-1-}$ mice from P0 to P70 except at $\mathrm{P} 21$, when hair follicles of $C D 109^{-1-}$ mice were difficult to count because of distortion of the hair follicles. Oil Red $\mathrm{O}$ staining of the skin of $C D 109^{-1-}$ mice revealed accumulation of sebum in the ectatic hair follicles (Figure $3 \mathrm{C}$ ). Inflammatory cell infiltration was observed in the dermis of $C D 109^{-1-}$ mice, which was accompanied by the appearance of skin appendage abnormalities (Figure 3B; see also Supplemental Figure S2 at http://ajp.amjpathol. org). The infiltrating cells included $\mathrm{CD}^{+}$cells (T lymphocytes), $\mathrm{Gr}-1^{+}$cells (neutrophils), and a small number of $\mathrm{CD}_{45 \mathrm{R}^{+}}$cells (B lymphocytes) (see Supplemental Figure S2 at http://ajp.amjpathol.org).

Hyperplasia of the epidermis and sebaceous glands became apparent at P7 in CD109-/- mice (Figure 3B; see also Supplemental Figure S1 at http://ajp.amjpathol. org), and were sustained until P70. Epidermal thickness of the dorsal skin was quantified by measuring the length between the basal lamina and the lower border of the stratum corneum; differences between $C D 109^{+/+}$and CD109 ${ }^{-1-}$ mice (three mice per group) were statistically analyzed. Significant differences were observed between the two groups at all time points after P7 except for P35 and P42 (Figure 3D). Epidermal hyperplasia was also observed at infundibular portions of hair follicles in CD109 ${ }^{-1-}$ mice. Epidermal hyperplasia was noted in dorsal skin and in sole skin, which does not have hair (Figure 4B). These findings indicated that CD109 deficiency causes epidermal hyperplasia accompanied by ectatic hair follicles and impairment of normal hair growth.

\section{Thickening of the Basal and Suprabasal Layers Is the Cause of Epidermal Hyperplasia}

To further investigate the epidermal hyperplasia, the dorsal skin epidermis of $C D 109^{+/+}$and $C D 109^{-/-}$mice was analyzed at $\mathrm{IHC}$ using proliferation, differentiation, and apoptotic markers (Figure 4, A and C). Compared with epidermis in $C D 109^{+/+}$mice, the epidermis of $C D 109^{-/-}$ mice exhibited apparent thickening of the basal and suprabasal layers, which were positive for the basal cell markers p63 and CK14. ${ }^{33,34}$ Thickness of the spinous and granular layers, which were positive for CK10 and filaggrin, respectively, were similar between $C D 109^{+/+}$ and $C D 109^{-1-}$ mice. We also examined the sole skin of adult $C D 109^{+/+}$and $C D 109^{-/-}$mice at P56. Epidermal hyperplasia and basal and suprabasal layer thickening 


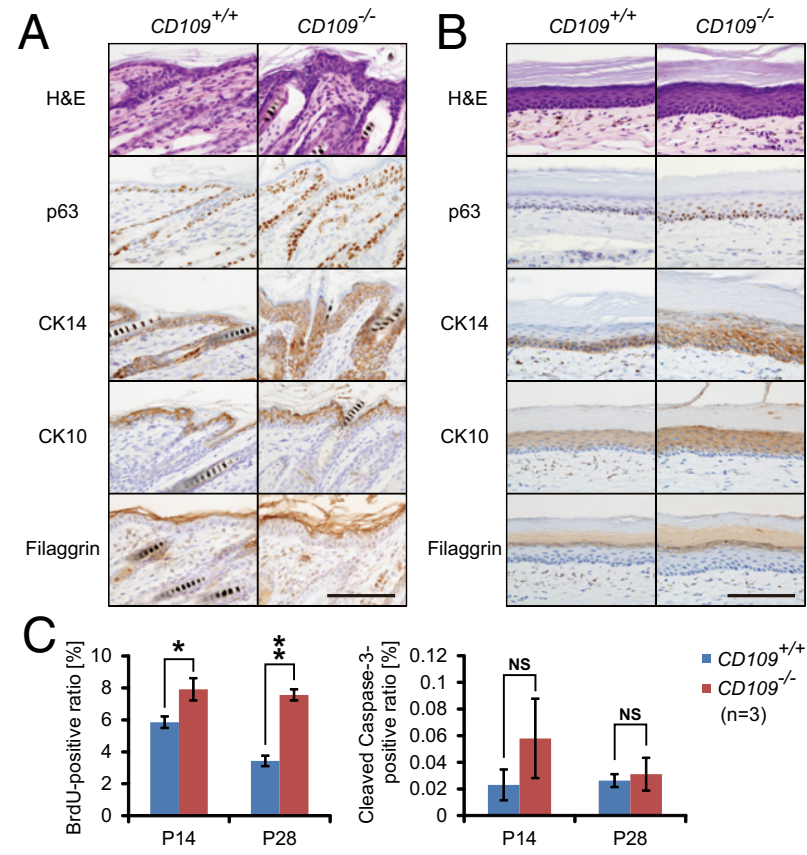

Figure 4. CD109 deficiency causes thickening of the epidermal basal and suprabasal layers. A and $\mathbf{B}$ : Immunohistochemical analysis of the epidermis of $\mathrm{CD} 09^{+/+}$and $\mathrm{CD} 109^{-/-}$mice. Dorsal (A) and sole (B) skin sections from $\mathrm{CD} 09^{+/+}$and $\mathrm{CD} \mathrm{O9}^{-/-}$mice were immunostained using antibodies against p63, cytokeratin (CK) 14, CK10, and filaggrin. Thickening of the basal and suprabasal layers, which were positive for p63 and CK14, was observed in $C D 109^{-/-}$mice compared with $C D 109^{+/+}$mice. No apparent difference was observed in the spinous and granular layers, which were positive for CK10 and filaggrin, respectively, between $\mathrm{CD}_{109^{+/+}}$and $\mathrm{CD} 109^{-/-}$mice. All images in $\mathbf{A}$ and $\mathbf{B}$ are the same magnification. Scale bars $=100 \mu \mathrm{m}$. $\mathbf{C}$ The ratios of BrdU-positive cells or cleaved caspase-3-positive cells in epidermis of $C D 109^{+/+}$and $C D 109^{-1-}$ mice. Whereas no significant difference was detected in cleaved caspase-3-positive ratio between $C D 109^{+/+}$and $C D 109^{-/-}$mice, the BrdU-positive ratio was significantly increased in the epidermis of $C D 109^{-/-}$mice compared with $C D 109^{+/+}$mice at P14 and P28 $(n=3)$. NS, not significant. ${ }^{*} P<0.05 ;{ }^{* *} P<0.01$.

were observed in the glabrous epidermis of $C D 109^{-1-}$ mice (Figure 4B), which suggested that the presence of hair follicles is not related to epidermal hyperplasia in CD109-deficient mice. Proliferation of the basal cells was assessed via BrdU incorporation, and apoptosis of keratinocytes was assessed by cleaved caspase-3 staining. Although no significant difference in the cleaved caspase-3-positive ratio was detected between the two mouse groups (Figure 4D), the BrdU-positive ratio was significantly increased in the epidermis of $C D 109^{-1-}$ mice compared with $C D 109^{+/+}$mice (Figure 4C; see also Supplemental Figure S3 at http://ajp.amjpathol.org). These findings suggest that CD109 regulates proliferation and differentiation of keratinocytes.

\section{Effect of CD109 Deficiency on TGF- $\beta$ Signal Is Undetectable in Epidermis}

CD109 is a component of the TGF- $\beta$ receptor complex, and inhibits TGF- $\beta /$ Smad signaling in vitro. ${ }^{25-27}$ To understand the mechanism underlying the epidermal hyperplasia and appendage abnormalities in CD109-deficient mice, we examined the influence of CD109 deficiency on TGF- $\beta /$ Smad signaling using fluorescence IHC. Smad2 phosphorylation, which is reportedly increased by knockdown of CD109 expression, ${ }^{26}$ was assessed in the epidermis by staining with anti-pSmad2 antibody. However, we found no significant difference in the number of pSmad2-positive cells in the epidermis between CD109 ${ }^{+/+}$ and $C D 109^{-1-}$ mice (four mice per group) from P7 to P28 (Figure 5A; see also Supplemental Figure S4 at http:// ajp.amjpathol.org). We also examined expression of the TGF- $\beta$-inducible protein Smad7 in the epidermis, which negatively regulates the strength and duration of TGF- $\beta$ signaling. ${ }^{35}$ No apparent difference in Smad7 staining was observed between $C D 109^{+/+}$and $C D 109^{-/-}$mice (data not shown)
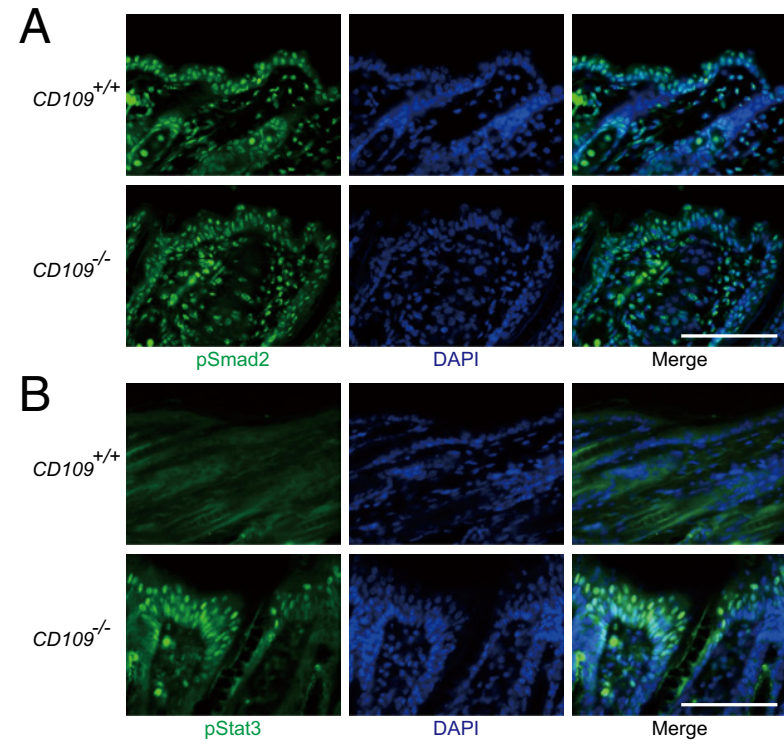

C
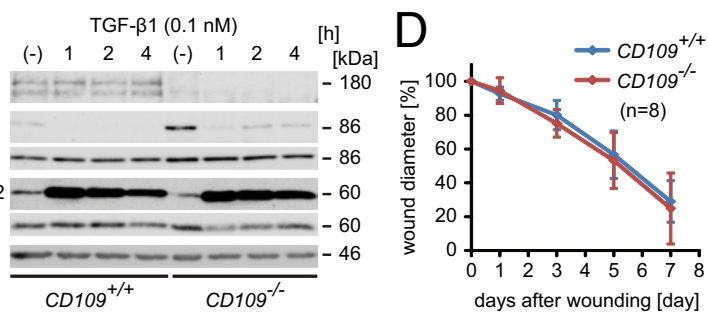

Figure 5. TGF- $\beta$ signal activation was undetectable, but Stat 3 phosphorylation was enhanced in the epidermis of CD109-deficient mice. A: Fluorescence immunostaining of $\mathrm{pSmad} 2$ in the epidermis of $C D 109^{+/+}$and $C D 109^{-/-}$mice. Dorsal skin sections from $C D 109^{+/+}$and $C D 109^{-1-}$ mice at P14 were immunostained using an antibody against pSmad2. A similar nuclear staining was observed in epidermis of both $\mathrm{CD}_{109^{+/+}}$and $\mathrm{CD}_{109^{-/-}}$mice. Nuclear counterstaining was performed using DAPI. All images are the same magnification. Scale bar $=100 \mu \mathrm{m}$. B: Fluorescence immunostaining of pStat 3 in the epidermis of $C D 109^{+/+}$and $C D 109^{-}$ mice. Dorsal skin sections from $\mathrm{CD}_{109^{+/+}}$and $\mathrm{CD} 109^{-/-}$mice at P14 were immunostained using an antibody against pStat3. The level of pStat3 was elevated in the epidermis of $C D 109^{-/-}$mice compared with $C D 109^{+/+}$ mice. Nuclear counterstaining was performed using DAPI. Scale bar $=100$ $\mu \mathrm{m}$. C: Time course of pStat 3 and $\mathrm{pSmad} 2$ after TGF- $\beta_{1}(0.1 \mathrm{nmol} / \mathrm{L}) \mathrm{stim}-$ ulation in $\mathrm{CD} \mathrm{OS}^{+/+}$and $\mathrm{CD} 109^{-/-}$keratinocytes. Phosphorylation of Stat3 and Smad2 was determined using Western blot analysis. Levels of pSmad2 induced by TGF- $\beta_{1}$ in $C D 109^{+/+}$and $C D 109^{-/-}$keratinocytes were almost the same at each time point, whereas levels of pStat3 in $C D 109^{-/-}$keratinocytes were significantly elevated under growth factor-free conditions compared with those in $C D 109^{+/+}$keratinocytes. Expression of total Stat3 and $\mathrm{Smad} 2$ is also shown. Expression of $\beta$-actin is shown as a loading control. D: In vivo wound healing assay in $\mathrm{CD} 109^{+/+}$and $\mathrm{CD} 109^{-/-}$mice. The assay was performed as described in Materials and Methods. No significant difference was observed between $C D 109^{+/+}$and $C D 109^{-/-}$mice. 


\section{Stat3 Phosphorylation Was Enhanced in the Epidermis of CD109 ${ }^{-/-}$Mice}

Recently, recombinant CD109 protein was reported to both down-regulate TGF- $\beta$ signaling and up-regulate STAT3 phosphorylation in human N/TERT-1 keratinocytes in vitro. ${ }^{28}$ In addition, STAT3 reportedly affects psoriasislike epidermal hyperplasia. ${ }^{36,37}$ To examine the effect of CD109 deficiency on Stat3 activation in vivo, we assessed Stat3 phosphorylation in the epidermis by staining with anti-pStat3 antibody. We found that Stat3 phosphorylation levels were significantly elevated in the epidermis of $C D 109^{-1-}$ mice compared with that of CD109 ${ }^{+/+}$mice, on and after P7 (Figure 5B; see also Supplemental Figure S5 at http://ajp.amjpathol.org). We also isolated primary keratinocytes from neonatal (PO) dorsal skin and examined Stat3 phosphorylation and TGF- $\beta /$ Smad signaling induced by TGF- $\beta_{1}$ in them. Primary keratinocytes were cultured for at least 7 days; Stat3 phosphorylation was assessed in the absence or presence of TGF- $\beta_{1}$. The level of Stat3 phosphorylation in CD109 ${ }^{-1-}$ keratinocytes was high without TGF- $\beta_{1}$ stimulation compared with that in $C D 109^{+/+}$keratinocytes, although the levels of Stat3 phosphorylation were decreased by TGF- $\beta_{1}$ stimulation in both $C D 109^{+/+}$and CD109 ${ }^{-1-}$ keratinocytes (Figure 5C). However, the levels of Smad2 phosphorylation induced by TGF- $\beta_{1}$ were almost the same at each time point between $C D 109^{+/+}$and CD109 ${ }^{-1-}$ keratinocytes (Figure 5C).

In addition, we performed an in vivo wound healing assay to evaluate the effect of CD109 on wound healing, which is regulated not only by TGF- $\beta$ signaling ${ }^{38}$ but also by Stat3 phosphorylation. ${ }^{29,30,36}$ The dorsal skin of CD109 ${ }^{+/+}$and CD109 ${ }^{-/-}$mice was wounded via punch biopsy, and wound closure was measured as described in Materials and Methods. However, there was no significant difference in wound closure between CD109 ${ }^{+/+}$and $C D 109^{-1-}$ mice at each time point (Figure 5D).

\section{Discussion}

CD109 is a GPI-anchored cell surface protein that exhibits a confined expression to a limited number of cell types. Using Northern blot analysis, CD109 expression was detected only in human and mouse testes. ${ }^{8}$ Using IHC analyses, CD109 immunoreactivity was detected in human myoepithelial cells of the mammary, salivary, lacrimal, and bronchial glands, and basal cells of the prostate and bronchial epithelia. ${ }^{10,11}$ In the present study, we analyzed mouse CD109 expression using IHC, and detected CD109 in the epidermis of the skin, the squamous epithelium of the tongue, and the seminiferous tubules of the testes. However, we could not detect its expression in myoepithelial cells of the mammary and salivary glands or the basal cells of the bronchial epithelium, which indicates that the expression pattern of mouse CD109 is different from human CD109.

To investigate the function of CD109 in vivo, we generated $C D 109^{-1-}$ mice, which exhibited skin abnormalities but no apparent abnormalities in other tissues. Skin ab- normalities in $C D 109^{-1-}$ mice included epithelial hyperplasia, primarily due to basal and suprabasal layer thickening, with increased basal cell proliferation, impairment of hair growth, ectatic hair follicles, and sebaceous gland hyperplasia. Among these abnormalities, epithelial hyperplasia could be the primary phenotype as a result of CD109 deficiency because the epidermal hyperplasia was observed not only in the dorsal skin but also in the sole skin, which does not have skin appendages. Impairment of hair growth and ectatic hair follicles may be secondary changes caused by narrowing of the infundibular portion of the hair follicles due to epithelial hyperplasia, because no developmental or differentiation abnormalities were observed at histologic analysis from P0 to P5, and hyperplasia of epidermis and sebaceous glands emerged at P7, before kinked hair shafts and ectatic hair follicles at P14. Inflammatory cell infiltration was also observed in the skin of CD109-/- mice. The infiltrating cells included T Iymphocytes, neutrophils, and a small number of B lymphocytes. Although the precise mechanism of infiltration of these cells in the skin of $C D 109^{-1-}$ mice remains elusive, it may be due to psoriasis-like skin alterations $^{36,37}$ or to a reaction to accumulation of sebum. Alternatively, the inflammation might contribute to epidermal hyperplasia and hair follicle degeneration. Although CD109 is highly expressed in the seminiferous tubules of the testes in both humans and mice, CD109-/- mice did not exhibit any apparent abnormality in the testes; hence the function of CD109 in the testes remains unclear.

At $\mathrm{IHC}$ analyses of human cancer tissues, we have previously reported that CD109 is highly expressed in SCCs of the lung and oral cavity. ${ }^{10,14}$ In our study using SCCs of the oral cavity, CD109 was expressed in all well-differentiated SCCs, but in only $89 \%$ and $64 \%$ of moderately and poorly differentiated SCCs, respectively, which implies that CD109 expression is correlated with the differentiation stage of SCCs. In the present study, we found that CD109 deficiency results in thickening of the basal and suprabasal cell layers in the epidermis, with increased basal cell proliferation. These findings suggest that CD109 regulates proliferation and differentiation of keratinocytes in vivo, even in malignant tumors. Further investigation is necessary to clarify the role of CD109 in the development of cancer in humans.

CD109 is a negative regulator of TGF- $\beta$ signaling in keratinocytes in vitro; overexpression of CD109 inhibits TGF- $\beta$ signaling, whereas knockdown of CD109 up-regulates its signaling. ${ }^{25-28}$ Because activation of TGF- $\beta$ signaling suppresses cell proliferation of keratinocytes in vitro, ${ }^{17}$ we evaluated the status of Smad2, one of the R-Smads, and Smad7, one of the I-Smads, ${ }^{20-23}$ in CD109-1- mice. Cutaneous wound healing is reportedly delayed in transgenic mice that overexpress Smad2 in the epidermis, ${ }^{39}$ and hyperplasia of the epidermis and sebaceous glands is induced in transgenic mice that overexpress Smad7 in the epidermis. ${ }^{35,40}$ The skin phenotype of Smad7 transgenic mice was similar to that of CD109 ${ }^{-1-}$ mice observed in the present study. Epidermal hyperplasia in Smad7 transgenic mice may be due to suppression of R-Smad (eg, Smad2) phosphorylation and a reduction in TGFBRI and TGFBRII protein levels, 
resulting in blockage of TGF- $\beta$-induced growth arrest in keratinocytes. ${ }^{40}$ However, CD109 deficiency influenced neither levels of Smad2 phosphorylation and Smad7 expression nor wound-healing ability in the epidermis of $\mathrm{CD}_{109^{-1-}}$ mice. These findings suggest either that longlasting effects of CD109 deficiency on the TGF- $\beta$ signaling pathway may be masked by feedback signals or other compensatory mechanisms or that CD109 does not modulate TGF- $\beta /$ Smad2 signaling in mouse epidermis but is associated with a different signaling pathway.

CD109 can reportedly regulate STAT3 activation in human keratinocytes. ${ }^{28}$ In addition, up-regulation of STAT3 is associated with psoriasis, ${ }^{36,37}$ which is a common disease characterized histologically by epidermal hyperplasia, altered epidermal differentiation, and local accumulation of acute and chronic inflammatory cells. ${ }^{30,36,41}$ We therefore evaluated the level of Stat3 phosphorylation in CD109 ${ }^{-1-}$ mice. Immunofluorescence analysis showed that Stat3 phosphorylation was elevated in the epidermis of CD109 ${ }^{-/-}$mice compared with $C D 109^{+/+}$mice. Enhanced Stat3 phosphorylation was also observed in primary keratinocytes isolated from $C D 109^{-1-}$ mice under cytokine- and growth factor-free conditions, although TGF- $\beta_{1}$ stimulation markedly down-regulated Stat3 phosphorylation. Stat3 up-regulation is associated with increased proliferation and impaired differentiation of keratinocytes, and results in psoriasis-like skin alterations including hyperkeratosis and acanthosis with inflammatory infiltrates in vivo. ${ }^{30,36,37,41}$ This phenotype is similar to the skin abnormalities observed in $C D 109^{-I-}$ mice. Thus, our findings suggest that CD109 regulates Stat3 activation, which could be associated with epidermal hyperplasia in $C D 109^{-1-}$ mice. Further analyses of cytokine or growth factor signaling pathways will provide insight into the precise mechanism of skin abnormalities developed in $C D 109^{-1-}$ mice.

\section{Acknowledgments}

We thank Koichi Imaizumi, Kozo Uchiyama, and Akiko Itoh (Department of Pathology), Nobuyoshi Hamada and Yoshiyuki Nakamura (Radioisotope Center Medical Branch), and Yasutaka Ohya and Kumiko Yano-Ohya (Division for Research of Laboratory Animals, Center for Research of Laboratory Animals and Medical Research Engineering) for technical assistance.

\section{References}

1. Sutherland DR, Yeo E, Ryan A, Mills GB, Bailey D, Baker MA: Identification of a cell-surface antigen associated with activated $T$ lymphoblasts and activated platelets. Blood 1991, 77:84-93

2. Haregewoin A, Solomon K, Hom RC, Soman G, Bergelson JM, Bhan AK, Finberg RW: Cellular expression of a GPI-linked T cell activation protein. Cell Immunol 1994, 156:357-370

3. Smith JW, Hayward CP, Horsewood P, Warkentin TE, Denomme GA, Kelton JG: Characterization and localization of the Gova/b alloantigens to the glycosylphosphatidylinositol-anchored protein CDw109 on human platelets. Blood 1995, 86:2807-2814

4. Lin M, Sutherland DR, Horsfall W, Totty N, Yeo E, Nayar R, Wu XF, Schuh AC: Cell surface antigen CD109 is a novel member of the
alpha(2)-macroglobulin/C3, C4, C5 family of thioester-containing proteins. Blood 2002, 99:1683-1691

5. Kelton JG, Smith JW, Horsewood P, Humbert JR, Hayward CP, Warkentin TE: Gov a/b alloantigen system on human platelets. Blood 1990, 75:2172-2176

6. Murray LJ, Bruno E, Uchida N, Hoffman R, Nayar R, Yeo EL, Schuh AC, Sutherland DR: CD109 is expressed on a subpopulation of $\mathrm{CD}_{3}{ }^{+}$cells enriched in hematopoietic stem and progenitor cells. Exp Hematol 1999, 27:1282-1294

7. Giesert C, Marxer A, Sutherland DR, Schuh AC, Kanz L, Burring H-J: Antibody W7C5 defines a CD109 epitope expressed on CD34 ${ }^{+}$and CD34- hematopoietic and mesenchymal stem cell subsets. Ann NY Acad Sci 2003, 996:227-230

8. Hashimoto M, Ichihara M, Watanabe T, Kawai K, Koshikawa K, Yuasa N, Takahashi T, Yatabe Y, Murakumo Y, Zhang JM, Nimura Y, Takahashi M: Expression of CD109 in human cancer. Oncogene 2004, 23:3716-3720

9. Zhang JM, Hashimoto M, Kawai K, Murakumo Y, Sato T, Ichihara M, Nakamura S, Takahashi M: CD109 expression in squamous cell carcinoma of the uterine cervix. Pathol Int 2005, 55:165-169

10. Sato T, Murakumo $Y$, Hagiwara $S$, Jijiwa M, Suzuki $C$, Yatabe $Y$, Takahashi M: High-level expression of CD109 is frequently detected in lung squamous cell carcinomas. Pathol Int 2007, 57:719-724

11. Hasegawa M, Hagiwara S, Sato T, Jijiwa M, Murakumo Y, Maeda M, Moritani S, Ichihara S, Takahashi M: CD109, a new marker for myoepithelial cells of mammary, salivary, and lacrimal glands and prostate basal cells. Pathol Int 2007, 57:245-250

12. Hasegawa M, Moritani S, Murakumo Y, Sato T, Hagiwara S, Suzuki C, Mii S, Jijiwa M, Enomoto A, Asai N, Ichihara S, Takahashi M: CD109 expression in basal-like breast carcinoma. Pathol Int 2008, 58:288294

13. Järvinen AK, Autio R, Kilpinen S, Saarela M, Leivo I, Grénman R, Mäkitie AA, Monni O: High-resolution copy number and gene expression microarray analyses of head and neck squamous cell carcinoma cell lines of tongue and larynx. Genes Chromosomes Cancer 2008, 47:500-509

14. Hagiwara S, Murakumo Y, Sato T, Shigetomi T, Mitsudo K, Tohnai I, Ueda M, Takahashi M: Up-regulation of CD109 expression is associated with carcinogenesis of the squamous epithelium of the oral cavity. Cancer Sci 2008, 99:1916-1923

15. Ohshima Y, Yajima I, Kumasaka MY, Yanagishita T, Watanabe D, Takahashi M, Inoue Y, Inn H, Matsumoto Y, Kato M: CD109 expression levels in malignant melanoma. J Dermatol Sci 2010, 57:140-142

16. Hagikura M, Murakumo Y, Hasegawa M, Jijiwa M, Hagiwara S, Mii S, Hagikura S, Matsukawa Y, Yoshino Y, Hattori R, Wakai K, Nakamura S, Gotoh M, Takahashi M: Correlation of pathological grade and tumor stage of urothelial carcinomas with CD109 expression. Pathol Int 2010, 60:735-743

17. Rahimi RA, Leof EB: TGF- $\beta$ signaling: a tale of two responses. J Cell Biochem 2007, 102:593-608

18. Massagué J: TGF $\beta$ in cancer. Cell 2008, 134:215-230

19. Li MO, Flavell RA: TGF- $\beta$ : a master of all T cell trades. Cell 2008, 134:392-404

20. Shi Y, Massagué J: Mechanisms of TGF- $\beta$ signaling from cell membrane to the nucleus. Cell 2003, 113:685-700

21. Schmierer B, Hill CS: TGF $\beta$-SMAD signal transduction: molecular specificity and functional flexibility. Nat Rev Mol Cell Biol 2007, 8:970-982

22. Moustakas $\mathrm{A}$, Heldin $\mathrm{CH}$ : The regulation of TGF $\beta$ signal transduction. Development 2009, 136:3699-3714

23. Itoh $\mathrm{S}$, ten Dijke P: Negative regulation of TGF- $\beta$ receptor/Smad signal transduction. Curr Opin Cell Biol 2007, 19:176-184

24. Tam BY, Germain L, Philip A: TGF- $\beta$ receptor expression on human keratinocytes: a $150 \mathrm{kDa}$ GPI-anchored TGF- $\beta 1$ binding protein forms a heteromeric complex with type I and type II receptors. J Cell Biochem 1998, 70:573-586

25. Finnson KW, Tam BY, Liu K, Marcoux A, Lepage P, Roy S, Bizet AA, Philip A: Identification of CD109 as part of the TGF- $\beta$ receptor system in human keratinocytes. FASEB J 2006, 20:1525-1527

26. Hagiwara S, Murakumo Y, Mii S, Shigetomi T, Yamamoto N, Furue H, Ueda M, Takahashi M: Processing of CD109 by furin and its role in the regulation of TGF- $\beta$ signaling. Oncogene 2010, 29:2181-2191

27. Bizet AA, Liu K, Tran-Khanh N, Saksena A, Vorstenbosch J, Finnson KW, Buschmann MD, Philip A: The TGF- $\beta$ co-receptor, CD109, pro- 
motes internalization and degradation of TGF- $\beta$ receptors. Biochim Biophys Acta 2011, 1813:742-753

28. Litvinov IV, Bizet AA, Binamer Y, Jones DA, Sasseville D, Philip A: CD109 release from the cell surface in human keratinocytes regulates TGF- $\beta$ receptor expression, TGF- $\beta$ signalling and STAT3 activation: relevance to psoriasis. Exp Dermatol 2011, 20:627-632

29. Yu H, Kortylewski M, Pardoll D: Crosstalk between cancer and immune cells: role of STAT3 in the tumour microenvironment. Nat Rev Immunol 2007, 7:41-51

30. Sano S, Chan KS, DiGiovanni J: Impact of Stat3 activation upon skin biology: a dichotomy of its role between homeostasis and diseases. J Dermatol Sci 2008, 50:1-14

31. Walia B, Wang L, Merlin D, Sitaraman SV: TGF- $\beta$ down-regulates IL-6 signaling in intestinal epithelial cells: critical role of SMAD-2. FASEB $J$ 2003, 17:2130-2132

32. Starsíchova A, Lincová E, Pernicová Z, Kozubík A, Soucek K: TGF- $\beta 1$ suppresses IL-6-induced STAT3 activation through regulation of Jak2 expression in prostate epithelial cells. Cell Signal 2010, 22:1734-1744

33. Parsa R, Yang A, McKeon F, Green H: Association of p63 with proliferative potential in normal and neoplastic human keratinocytes. J Invest Dermatol 1999, 113:1099-1105

34. Fuchs E: Epidermal differentiation: the bare essentials. J Cell Biol 1990, 111:2807-2814

35. He W, Li AG, Wang D, Han S, Zheng B, Goumans MJ, ten Dijke P, Wang $\mathrm{XJ}$ : Overexpression of Smad7 results in severe pathological alterations in multiple epithelial tissues. EMBO J 2002, 21:2580-2590

36. Sano S, Chan KS, Carbajal S, Clifford J, Peavey M, Kiguchi K, Itami S, Nickoloff BJ, DiGiovanni J: Stat3 links activated keratinocytes and immunocytes required for development of psoriasis in a novel transgenic mouse model. Nat Med 2005, 11:43-49

37. Zheng Y, Danilenko DM, Valdez P, Kasman I, Eastham-Anderson J, Wu J, Ouyang W: Interleukin-22, a $T_{H} 17$ cytokine, mediates IL-23induced dermal inflammation and acanthosis. Nature 2007, 445:648651

38. Werner S, Grose R: Regulation of wound healing by growth factors and cytokines. Physiol Rev 2003, 83:835-870

39. Hosokawa R, Urata MM, Ito $\mathrm{Y}$, Bringas P Jr, Chai Y: Functional significance of Smad2 in regulating basal keratinocyte migration during wound healing. J Invest Dermatol 2005, 125:1302-1309

40. Han G, Li AG, Liang YY, Owens P, He W, Lu S, Yoshimatsu Y, Wang $\mathrm{D}$, ten Dijke $\mathrm{P}$, Lin $\mathrm{X}$, Wang $\mathrm{XJ}$ : Smad7-induced $\beta$-catenin degradation alters epidermal appendage development. Dev Cell 2006, 11: 301-312

41. Wolk K, Haugen HS, Xu W, Witte E, Waggie K, Anderson M, Vom Baur E, Witte K, Warszawska K, Philipp S, Johnson-Leger C, Volk HD, Sterry W, Sabat R: IL-22 and IL-20 are key mediators of the epidermal alterations in psoriasis while IL-17 and IFN- $\gamma$ are not. J Mol Med 2009, $87: 523-536$ 